\title{
A Noção de conectivo nas gramáticas brasileiras do século XIX
}

\author{
The Notion of connective in the $19^{\text {th }}$ century \\ Brazilian grammars
}

\author{
Ricardo Cavaliere* \\ Universidade Federal Fluminense, Niterói, RJ, Brasil
}

\begin{abstract}
Resumo: Este trabalho visa a traçar um comentário genérico sobre o conceito de conectivo e sua descrição nas gramáticas brasileiras do século XIX. Nesse intuito, selecionaram-se dez gramáticas pertencentes aos dois períodos históricos que figuram no Brasil ao longo dos Oitocentos: o Período Racionalista, pautado nas teses da gramática filosófica, e o Período Científico, em sua fase inicial, pautado nas ideias linguístico-evolucionistas. O propósito deste estudo resume-se a conferir aos pesquisadores contemporâneos uma visão abrangente e segura sobre o papel que os gramáticos brasileiros conferiam ao conectivo, seja como classe gramatical, seja como termo sintático integrante da construção do enunciado frasal.
\end{abstract}

Palavras-chave: Conectivos. Gramática brasileira. Século XIX.

\begin{abstract}
This paper aims to draw a generic comment about the concept of connective and its description in the $19^{\text {th }}$ century Brazilian grammars of Portuguese language. In this purpose, ten grammars belonging to the two historical periods that appeared in Brazil throughout the $19^{\text {th }}$ century were selected: the Rationalist Period, based on the theses of the philosophical grammar, and the Scientific Period, in its initial phase, based on linguisticevolutionist ideas. The purpose of this study is to give contemporary researchers a comprehensive and secure view on the role that Brazilian grammarians confer to the connective, either as a part of the discourse or as a syntactic term that belongs to the construction of the sentence.
\end{abstract}

Keywords: Connectives. Brazilian grammar. 19th century.

\section{INTRODUÇÃo}

O século XIX testemunhou, no Brasil, o surgimento de duas vertentes de descrição gramatical do português fundadas em modelos teóricos distintos. De início, com o alvorecer do século, vem a lume o Epitome da gramática portuguesa (1806), obra com que Antônio de Morais Silva (1755-1824) inaugura o denominado período racionalista ${ }^{1}$ dos estudos linguísticos brasileiros. O fato de Morais Silva haver publicado o Epitome em Portugal tem motivado alguns historiógrafos da linguística a

\footnotetext{
* Professor do Departamento de Letras Clássicas e Vernáculas do Instituto de Letras da Universidade Federal Fluminense, Niterói, RJ, Brasil; ricardocavaliere@id.uff.br

${ }^{1}$ Sobre a periodização dos estudos linguísticos no Brasil, leia Nascentes (1939), Câmara Jr. (1972), Elia (1975), Cavaliere (2002).
} 
desconsiderá-lo como texto precursor da gramaticografia do português no Brasil, a que se alia a evidência de que, embora nascido no Rio de Janeiro, Morais Silva tenha sido súdito da Coroa portuguesa ${ }^{2}$. A melhor postura historiográfica é a de agasalhar o Epitome como obra gramatical brasileira, já que fruto de um gramático brasileiro, não obstante nascido em solo colonizado por Portugal ${ }^{3}$.

O Epitome pauta-se na descrição da língua à luz dos conceitos racionalistas de Port-Royal, mediante inspiração sensível em nomes como Étienne de Condillac (1715-1780), César Chesneau Dumarsais (1676-1756), Charles Pinot Duclos (17041772) e, mais diretamente, Antônio Soares Barbosa (1734-1801). Não nos cabe aqui determo-nos em análise aprofundada dessa obra tão significativa da história da linguística brasileira ${ }^{4}$. Cumpre-nos, tão somente, salientar que, na esteira do Epitome, vários foram os textos gramaticais publicados no Brasil a partir da criação da Impressão Régia em $1808^{5}$, em que as bases teóricas são fundamentalmente as mesmas, de cunho filosófico, motivo pelo qual ao longo de aproximadamente meio século se multiplicam os textos gramaticais que visam ao ensino da língua vernácula em sala de aula.

Citem-se, entre os gramáticos brasileiros mais proeminentes deste período, Inácio Felizardo Fortes (?-1856), Antônio da Costa Duarte (?-?), Filipe Benício Conduru (1818-1878) José Alexandre Passos (1808-1898), Francisco Sotero dos Reis (1800-1871), Charles Grivet (1816-1876), Antônio Alvares Pereira Coruja (18061889) e Ernesto Carneiro Ribeiro (1839-1920), entre outros. O legado mais visível que nos deixou a gramática racionalista brasileira foi a de um prescritivismo acentuado, sem fundamentação em corpus definido, característica que, efetivamente, sobrepõe-se à análise detida do fato linguístico à luz dos cânones doutrinários. Tal fato deixa transparecer, em leitura superficial, apenas a face meramente normativa dessas gramáticas, o que, a nosso juízo, não corresponde ao verdadeiro perfil dos textos produzidos no período em tela ${ }^{6}$.

A partir do último quartel do século XIX, surge no Brasil uma gramática do português erigida sobre os pilares do evolucionismo linguístico. Agora, em clara mudança de rumos paradigmáticos, a tarefa do gramático prescritivista, cujos cânones fundamentam-se em corpus de língua literária, irmana-se à do linguista interessado na descrição e análise dos fatos da língua à luz dos novéis conceitos trazidos pela escola de August Schleicher (1821-1868) e Wilhelm Scherer (18411886). Sai o normativismo de índole purista, entra a análise do fato linguístico mediante percurso de todas as áreas de descrição do português: fonética, morfologia (taxionomia, ptoseonomia), sintaxe, semântica, estilística. Na historiografia gramatical

\footnotetext{
2 Essa é uma questão que também atinge, por exemplo, os poetas árcades nascidos do século XVIII, embora já não se discuta se eram ou não brasileiros. Sobre o tema, leia Dal Ri Jr. (2002) e Dal Ri (2010).

3 Considere-se, a respeito, a expressiva nota "natural do Rio de Janeiro", que Morais Silva faz estampar na folha de rosto de seu Dicionário (1831[1789]).

${ }^{4}$ Sobre o Epítome, leia necessariamente Assunção (2001), Murakawa (2006) e Cavaliere (2006).

${ }^{5}$ A primeira gramática brasileira publicada pela Impressão Régia é a Arte de gramática portuguesa (1816), do Padre Inácio Felizardo Fortes (?-1856).

${ }^{6}$ Sobre o período racionalista, leia Cavaliere (2014[a]).
} 
brasileira, identifica-se este momento de nossa produção linguística como período científico. Nomes como Júlio Ribeiro (1845-1890), João Ribeiro (1860-1934), Fausto Barreto (1852-1908), Alfredo Gomes (1859-1924), Manuel Pacheco da Silva Júnior (1842-1899), José Ventura Bôscoli (1855-1919), Maximino de Araújo Maciel (18661923), entre outros, integram esse movimento tão profícuo de nossa produção gramatical, cujo legado inclui, além de gramáticas propriamente ditas, várias teses sobre linguística diacrônica, mormente no campo da morfologia. Também é desse período o primeiro texto sobre linguística geral publicado no Brasil: referimo-nos aqui ao opúsculo Traços gerais de linguística (Ribeiro, 1880), cujo teor perpassa temas nodais do evolucionismo linguístico, tais como o processamento da língua no cérebro, a produção dos sons pelo aparelho fonador e a linhagem hereditária das famílias linguísticas.

Em síntese, o panorama gramatical brasileiro no século XIX apresenta, a partir dos anos 1880, uma descontinuidade paradigmática claramente identificada pela introdução do modelo evolucionista, aliado às bases da gramática históricocomparativa, em um cenário antes dominado pelo modelo racionalista, cujos efeitos, no âmbito da difusão do saber linguístico, foram o de intensificar a produção de textos que serviam tanto ao escopo pedagógico quanto ao propósito investigador, fato que, decerto, desconstruiu a antiga ordem pedagógica e traçou novos rumos ao ensino do português como língua vernácula.

Quadro 1 - Perfil sintético da gramática brasileira do século XIX

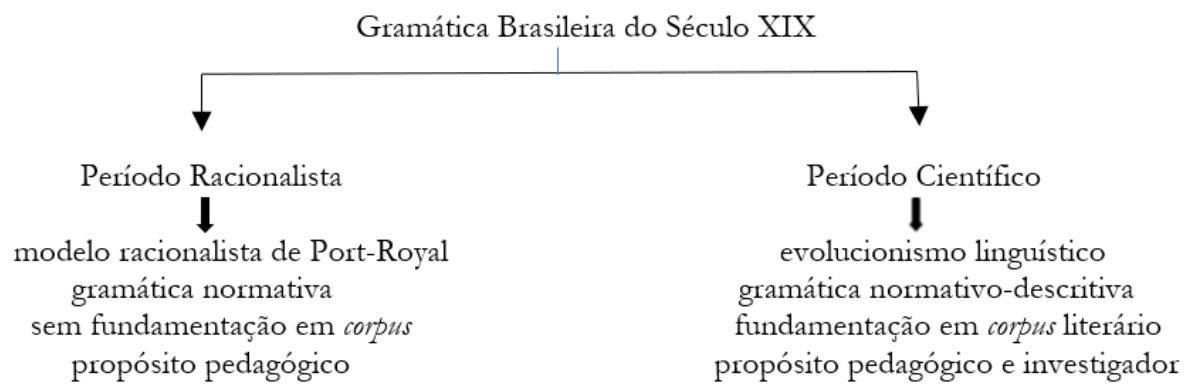

\section{FUNDAMENTOS DA GRAMÁTICA RACIONALISTA}

Antes de ingressarmos detidamente na conceituação dos conectivos, convém traçar juízo, ainda que em rápidas palavras, acerca da concepção de língua e de sua descrição nos modelos teóricos referidos. Iniciemos pelo modelo racionalista.

Pautada no princípio de que a língua é uma faculdade da razão humana, a gramática racionalista, também denominada gramática filosófica ou gramática razoada, trata o fenômeno linguístico mediante aparato teórico que originalmente se aplicava para o entendimento do raciocínio e das relações lógicas estabelecidas na construção do pensamento. Um deles, fundamental, é o conceito de $i d e i a$, assim entendido como uma imagem que se fixa no organismo humano através dos sentidos. Segundo os gramáticos racionalistas, os objetos que circundam o homem no cotidiano de sua existência firmam uma imagem representativa de todos os atributos que os caracterizam, de que decorre construírem-se, na mente humana, conceitos ou concepções imagísticas desses objetos, isto é, ideias conceituais (cf. Burgraff, 1863, p. 1). 
Esta noção de ideia remete necessariamente à de abstração, no sentido de que a imagem que se constrói na mente humana não se confunde com a coisa imaginada ou conceitualmente elaborada, já que se está aqui no plano imanente do raciocínio ${ }^{7}$. Em outros termos, na proposta racionalista, o mundo que conhecemos não é o mundo das coisas no plano fático, mas o mundo das construções imagísticas que fazemos dessas coisas, razão por que, ao estabelecermos relação entre os objetos, na realidade estamos relacionando entre si essas imagens conceituais, que são, por assim dizer, estratégias do raciocínio e da concepção lógica do mundo de que são dotados todos os homens. Para valer-se dessa faculdade, recorre o homem a atributos que lhe são característicos, tais como a percepção, a memória, a atenção e a imaginação (Burgraff, 1863, p. 1).

A presença dessas ideias na mente humana, ou no espirito humano, resulta em um mecanismo de relações ${ }^{8}$ que as vincula, normalmente uma comparação que lhes identifica semelhanças e dessemelhanças ou lhes atribuem relação de causa e efeito, relação de temporalidade entre tantas outras. $\mathrm{Na}$ concepção racionalista, as relações entre ideias conferem ao homem a faculdade do conhecimento das coisas, ou seja, cuida-se de um processo mental em que a realidade fática é transferida imagisticamente para o espírito, de que decorre a criação do conhecimento ou ciência do mundo. Alguns metatermos inerentes a esse processo cognitivo se encontram com expressiva frequência nas páginas das gramáticas racionalistas, entre eles a noção de juío e proposição. O primeiro resume-se na denominação que a lógica confere ao conhecimento na mente humana, ao passo que o segundo é a expressão do juízo no plano linguístico?.

Quadro 2 - Conceito dos metatermos juízo e proposição na gramática racionalista.

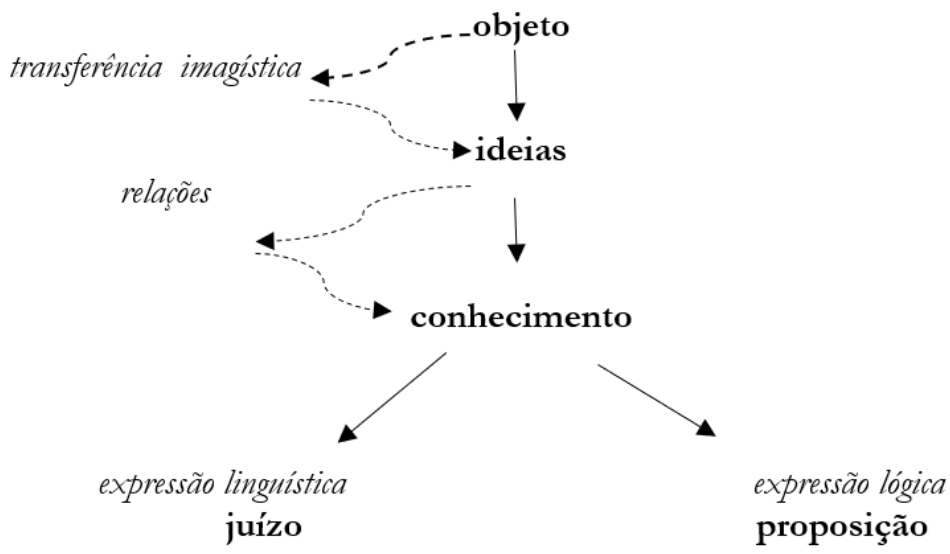

\footnotetext{
${ }^{7}$ Em certa medida, pode-se estabelecer uma analogia entre a relação ideia-coisa imaginada, no âmbito da gramática racionalista, com a relação significante-objeto na conceituação do signo saussuriano.

8 Burggraff adverte que, na gramática do francês, é comum usarem-se os termos relation e rapport indistintamente, embora considere ser mais conveniente reservar o termo relation para a comparação entre dois objetos do ponto de vista em que ela efetivamente se faz e rapport para o resultado da comparação. Exemplificando, Burggraff observa que na frase "être assis sur le bord d'une fontaine", a preposição sur assinala uma relation de vínculo e um rapport de superioridade (1863, p. 3-4).

9 Lembremo-nos aqui da concepção de gramática em Destutt-Tracy: "La grammaire est, dit-on, la science des signes. J'en conviens. Mais j'aimerais mieux que l'on dit, et sur-tout que l'on eût dit, de tout tems, qu'elle est la continuation de la science des idées" (1803, p. 1).
} 
Em outra dimensão, ao cuidarem da língua como atributo do homem, os gramáticos racionalistas se valem de um aparato teórico que serve originalmente ao estudo da razão humana, de que decorre, naturalmente, o uso de terminologia atinente à Filosofia, em especial no âmbito da Lógica. Aqui reside alguma dificuldade quanto ao tratamento da metalinguagem na leitura dos textos gramaticais antigos ${ }^{10}$, pois a dimensão conceitual que certos metatermos detêm nesses textos pode diferir significativamente da que hoje se lhes atribui. Vejamos o exemplo abaixo extraído de Reis (1871[1866], p. 33):

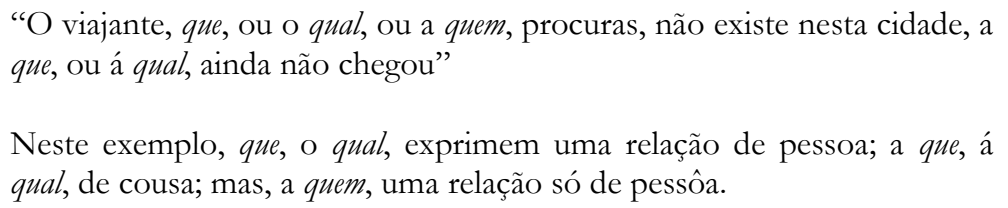

Observe-se que, ao descrever a ligação sintática entre os termos que se vinculam pelos pronomes relativos que e quem, Reis salienta que o uso de um e outro pronome submete-se a uma relação que não se expressa propriamente no plano linguístico, senão no plano conceitual: "relação de pessoa" e "relação de coisa". Em outras palavras, a justificação que o gramático encontra para o uso desse ou daquele pronome relativo não se constrói no plano estritamente linguístico, mas sim no plano ideativo. Comparemos com o que diz um gramático do século XX (Melo, 1970, p. 276), que cuida do tema em perspectiva estritamente linguística:

Que é relativo fundamental, que pode ser substituído por o qual (a qual, os quais, as quais), desde que o antecedente seja substantivo [...] Quem, na língua atual, só se emprega com referência a pessoa ou coisa personificada, e pode vir preposicionado, de acordo com a função que desempenha.

Aqui, o emprego de que e quem depende do valor semântico do antecedente substantivo que expressa coisa ou substantivo que expressa pessoa -, ou seja, trata-se de uma descrição que não ultrapassa o plano sintático-semântico da gramática, bem diferente da proposta racionalista, que remete o fato sintático ao plano abstrato das relações ideativas.

Não obstante admitam a existência de línguas particulares, que se caracterizam por ter regras de construção frasal próprias, representativas das diversas nações ${ }^{11}$, a premissa do modelo racionalista é de que todas as línguas conhecidas são dotadas de universais linguísticos: a existência necessária de vogais e consoantes, tempos e modos verbais, relações sintáticas subjetivas e predicativas, classes gramaticais comuns, tais como o nome, o verbo, a preposição e o advérbio etc. Em decorrência, a par de uma gramática particular, há uma gramática geral, que cuida de leis gerais ${ }^{12}$ que dizem respeito à natureza própria do homem, do fato de todos os

10 Sobre o adequado tratamento da metalinguagem no estudo historiográfico, leia-se (Koerner, 1995), (Bartlett, 1984).

${ }^{11}$ Leia-se: "L'emsemble des mots, avec toutes leurs formes, dont se sert une nation pour exprimer ses connaissances, est ce qui constitue as langue particulière" (Burggraff, 1863, p. 4).

12 Sobre o conceito de leis na gramática racionalista, leia especialmente Ricken (s.d.). Convém advertir que o termo lei, aqui, não assume o sentido que viria a ter no âmbito da escola neogramática, de caráter evolucionista. 
homens serem dotados dos órgãos produtores de sons e da mesma inteligência que estabelece relações entre ideias. Em outras palavras, se a arquitetura mental para produção do conhecimento e elaboração do juízo é o mesmo em todos os homens, então, naturalmente, a construção das proposições haverá de seguir os mesmos princípios em todas as línguas, conforme se lê na seguinte passagem do maranhense Antônio da Costa Duarte (1877[1829], p. 7):

$\mathrm{Na}$ formação de seus pensamentos é uniforme, unico, e immutavel o procedimento do espirito humano; pois que todo o homem, de qualquer Nação que seja, pensa porque tem idéas, e comparando-as aprende as relações que entre ellas há: mas como entre as operações de nosso espirito e a Linguagem articulada, por meio da qual se exprimem, ha uma intima conexão e correspondencia; é forçoso que esta mesma imutabilidade se comunique ás linguas de todos os Povos.

Em consonância com o que aqui se disse, chegamos a alguns exemplos de definição de gramática em obras brasileiras do período racionalista, conforme exemplário seguinte:

a) Grammatica e arte, que ensina a declarar bem os nossos pensamentos, por meyo de palavras (Silva, 1806, p. 9).

b) A Grammatica divide-se em Grammatica Geral e Grammatica Particular. A Grammatica Geral é a sciencia dos princípios immutaveis e geraes da palavra pronunciada ou escripta em todas as línguas. A Grammatica particular é a arte de aplicar aos princípios immutaveis e geraes da palavra as instituições arbitrarias e usuaes de qualquer lingua. Grammatica Portugueza, pois, é a arte de aplicar aos princípios immutaveis e geraes da palavra os usos e idiotismos da língua portugueza. Grammatica portugueza tambem se pode definir a arte de falar e escrever correctamente a língua portugueza (Reis, 1871[1866], p. V-VII).

c) Grammatica Portugueza é a Arte que ensina a falar, ler, e escrever sem erros a Língua Portugueza (Duarte, 1877 [1829], p. 9).

d) Grammatica Portugueza é a arte que ensina a falar, escrever e ler com acerto a língua portugueza (Condurú, 1840, p. 5).

\section{FUNDAMENTOS DA GRAMÁTICA CIENTÍFICA}

Conforme acima referido, a primeira edição, em 1881, da Gramática portuguesa, de Júlio Ribeiro, inaugura uma nova fase na historiografia dos estudos gramaticais brasileiros, inspirada no evolucionismo linguístico e na doutrina históricocomparativista. Essa vertente, a que denominamos gramática científica ${ }^{13}$ no panorama historiográfico brasileiro, ingressa na gramaticografia brasileira como natural efeito dos estudos histórico-comparativistas desenvolvidos no Velho Mundo. O traço de modernidade que distingue a nova ordem reside na descrição da língua com foco sobre o fato concreto, ou, como se costumava dizer, sobre a 'matéria

${ }^{13}$ Em Cavaliere (2000), denominamos gramática científica este período que se inicia com Júlio Ribeiro (1845-1890) — pautado na nova 'ciência da linguagem' — e se encerra com a geração de gramáticos que surge na terceira década do século XX. Sílvio Elia (1975) opta pela denominação período científico, que, em sua concepção, se estende até meados do século XX. Sobre os parâmetros da gramática científica, leia também Fávero e Molina (2006), Santos (2010), Parreira (2011) e Gonçalves (2012). 
linguística', em detrimento da especulação meramente conceitual. Em outros termos, rompia-se com o mentalismo severo da escola racionalista, para ingressar-se com entusiasmo no empirismo envolvente que as ciências naturais tanto fizeram disseminar já nas primeiras décadas do século XIX.

As teses mais presentes nessa fase da gramaticografia brasileira pautam-se, como já se afirmou, no evolucionismo linguístico, entendido como o paradigma que busca identificar a origem da língua e as leis que regem sua evolução como ser análogo aos seres vivos. Sob inspiração da Biologia e da História Natural, Schleicher introduz as teses da evolução dos seres vivos ${ }^{14}$ para edificar uma árvore genealógica das línguas indo-europeias ${ }^{15}$, cujos reflexos se podem verificar mais concretamente na maneira como os linguistas passaram a interpretar o próprio fenômeno da língua, que deixa de ser uma consequência da faculdade da razão humana, submetida às relações mentais, para ser dotada de regras próprias que disciplinam sua evolução e sua caracterização como atributo do homem.

Destarte, no plano da ciência linguística, é com grande entusiasmo que os compêndios gramaticais brasileiros se deixam atrair pelas novéis propostas, cujas fontes imediatas eram sobretudo as gramáticas inglesas, francesas e portuguesas. Citem-se, por exemplo, os volumes lusitanos $A$ lingua portugueza; phonologia, etymologia, morphologia e syntaxe (1868) e A lingua portugueza; noções de glotologia geral e especial portugueza (1881), de Francisco Adolfo Coelho (1847-1919), além da Gramática portuguesa elementar; fundada sobre o método histórico-comparativo (1876), de Teófilo Braga (1843-1924). Igualmente relevantes, sobretudo na teoria sintática, a Grammaire comparée de la langue française (1885 [1876]), obra de Nicolas-Louis Cyprien Ayer (18251884), que obteve intensa repercussão na pesquisa e ensino de língua vernácula no Brasil, e A higher English gramar (1875), de Alexander Bain (1818-1903).

O que se abstrai da avaliação criteriosa dos textos publicados no período da gramática científica brasileira é um conceito plural de gramática, que se define em função do objeto específico de determinada área de pesquisa: gramática geral, que trata das leis universais da língua; gramática descritiva, que cuida da exposição sistemática de uma dada língua particular; gramática histórica, que visava ao restabelecimento do percurso diacrônico da língua; gramática prática, de caráter ordinariamente prescritivo, que se voltava exclusivamente para o ensino de língua materna. Observe-se que, no plano metalinguístico, parece haver uma linha de continuidade que perpassa do período racionalista ao período científico, conforme se observa nos termos gramática geral, leis, lingua particular, todos eles presentes nas duas escolas. A questão resolve-se, primeiro, pela constatação de que, no curso das ideias linguísticas, não há propriamente uma sequência de ruptura paradigmática, senão uma superposição de paradigmas que fluem em linhas de continuidade e descontinuidade, porém sempre presentes no ambiente acadêmico ${ }^{16}$. Por outro lado, evidencia-se que os metatermos

${ }^{14}$ Sobre a controversa ligação entre Schleicher e Charles Darwin (1809-1882), leia Koerner (1995, p. 62).

15 O método desenvolvido por August Schleicher para a reconstituição histórica das línguas (Stammbaumtheorie) — de grande repercussão no Brasil — é inspirado nos princípios de classificação botânica, em gêneros e espécies.

16 Sobre continuidades e descontinuidades no desenvolvimento da Linguística, leia especialmente (Koerner, 1989). 
sofrem ajustes de significação teórica, pois não permanecem, a toda evidência, petrificados nos conceitos que antes expressavam. Assim, por exemplo, gramática geral não cuida propriamente de universais na língua como resultantes da unicidade do raciocínio lógico no ser humano, mas de universais como identidades de caráter fonéticos, sintáticos, morfológicos, lexicais etc., que se revelam no plano eminentemente linguístico, sem qualquer fundamento filosófico. Igualmente, advirtase para a presença do termo leis em ambos os movimentos teóricos, cujo sentido difere significativamente.

Em outra dimensão, as melhores gramáticas brasileiras do período científico, conforme já ressaltado, a despeito de terem efetivo caráter prescritivo, jamais se desviaram totalmente de um escopo descritivo, o que lhes dá feição híbrida, descritivo-prescritiva, bastante diferente da que caracteriza os antigos compêndios normativos que se limitavam a arrolar sinteticamente as regras do uso correto da língua. A feição genérica da gramática brasileira do período científico, portanto, espelha uma formulação em que coexistem os aspectos universal, descritivo e prescritivo. Nos melhores volumes, esta concepção tridimensional integra as preocupações do gramático, com natural ênfase em um dos aspectos, via de regra o descritivo.

A presença do aspecto universal, sem dúvida, resulta da própria perspectiva universalista da linguística do século XIX, com suas leis gerais sobre a concepção da língua. Em sua definição de gramática, Maximino Maciel (1866-1923) afirma que se trata da "systematização logica dos factos e normas de uma língua qualquer" (1922 [1894], p. 1). Os termos presentes nessa definição merecem atenta reflexão, pois atuam como ícones do pensamento linguístico da época. A busca de uma "systematização logica" inscreve-se no ideário positivista da ordenação dos fatos como premissa de análise, além de servir de investigação empírica eficaz. Nesse sentido, a sinopse das gramáticas trazidas a lume no período científico — em que, via de regra, se alinham três grandes setores: fonologia, lexiologia e sintaxe - é extremamente precisa na denominação e hierarquização da matéria desenvolvida. Fatos e normas são termos de referência na linguística do século XIX, que, na busca das leis gerais que regem a evolução da língua, mergulha na análise diacrônica das línguas vernáculas modernas, com retorno necessário às fontes clássicas, de tal sorte que se possam descrever e comparar seus elementos constituintes.

O cunho universalista da definição de Maciel, entretanto, reside na expressão "língua qualquer". Seu uso implica uma visão do fato gramatical no nível mais abstrato que então se podia conceber: o das leis universais que configuram a própria gênese da linguagem humana. O próprio Maciel ratifica essa postura ao definir "gramática geral" ou "glossologia" como o tratado das "normas gerais e abstractas que se poderiam applicar á expressão do pensamento ou á linguagem" (1922 [1894], p. 2).

Esse conceito de gramática denota intenção de reposicionar o objeto da pesquisa gramatical, que sai do locus menor da língua vernácula para o locus mais amplo da "expressão do pensamento" ou da "linguagem". Há uma preferência latente pelo termo glossologia na definição de Maciel, que bem revela a percepção do linguista de que o uso de gramática para conceituar área de investigação tão abstrata poderia implicar entendimento deturpado da exata dimensão deste estudo. Em outra 
definição de gramática, essa residente no opúsculo Philologia portugueza, Maciel ratifica a tese do estudo universalista (1889: p. 1):

Grammatica é o tractado dos factos e dos phenomenos da linguagem em todas as suas manifestações exteriores.

Em accepção mais ampla e considerada sob o domínio philologico, a grammatica pode definir-se - o estudo circunstanciado e methodico dos phenomenos e das leis da linguagem humana.

$\mathrm{Na}$ verdade, a gramática brasileira pautada na escola histórico-comparativa não tinha olhos para o estudo mentalista da linguagem humana. O campo de atuação circunscrevia-se ao estudo "material" da língua, com notável ênfase, ipso facto, na fonologia (que trata dos "elementos materiais") e na morfologia (voltada para os elementos orgânicos). Nesse sentido, as bases epistemológicas que norteavam a História Natural, a Física e a Biologia passaram a ser empregadas analogamente na Linguística, que, assim, intitulava-se "ciência da linguagem".

A título de maior exemplificação, leiam-se as definições de gramática do período em tela:

a) Considerada de modo theorico, pode a grammatica definir-se a sciencia da linguagem: é seu objeto o estudo das leis ou normas segundo as quaes se exprime o pensamento pela linguagem, quer escripta, quer falada (Ribeiro, 1890, p. 3).

b) Grammatica é o estudo das leis que regem o desenvolvimento da linguagem humana (Bôscoli, 1998[1993], p. 11).

c) Grammatica é systematização logica dos factos e normas de uma língua qualquer (Maciel, 1922 [1894], p.1).

d) Gramatica é a exposição methodica dos factos da linguagem (Ribeiro, 1910[1881], p. 1).

e) Grammatica Geral é o estudo dos factos e das leis da linguagem em toda sua extensão [...]. O objeto da grammatica portugueza, é pois o estudo geral, descriptivo, histórico, comparativo e coordinativo, mas tão somente no dominio da língua portugueza, dos factos da linguagem e das leis que os regem (Silva Jr \& Andrade, 1887, p. 6-7).

\section{A NOÇÃo DE CONECTIVO E SUA REPERCUSSÃO NA DESCRIÇÃO DO PORTUGUÊS}

Neste estudo, utilizamos um corpus constituído de dez gramáticas brasileiras oitocentistas, cinco filiadas ao período racionalista e cinco publicadas no período científico. São elas:

1. Silva, Antonio de Moraes. Epitome da grammatica da lingua portuguesa (1806).

2. Duarte, Antonio da Costa. Compendio da grammatica philosophica da língua portugueza (1877[1829]).

3. Conduru, Felipe Benício de Oliveira. Gramática elementar da língua portuguesa (1840). 
4. Reis, Francisco Sotero. Grammatica portugueza, acomodada aos princípios geraes da palavra seguidos de immediata applicação pratica (1871[1866?]).

5. Costa e Cunha, Antonio Estevam da. Grammatica elementar portugueza (1880).

6. Ribeiro, João. Grammatica portugueza, curso superior (1930[1889]).

7. Ribeiro, Julio. Grammatica portuguesa (1911[1881]).

8. Silva Jr., Manuel Pacheco da \& Andrade, Boaventura P. Lameira de. Noções de grammatica portuguesa (1887).

9. Bôscoli, José Ventura. Grammatica portuguesa (1898 [1893]).

10. Maciel, Maximino. Philologia portugueza: ensaios descriptivos e historicos sobre a lingua vernácula (1889).

Uma consulta superficial às dez gramáticas de que nos servimos revela uma descrição heterogênea das classes gramaticais. Observe-se que, embora haja certo equilíbrio quanto ao número de classes, algumas delas, como no caso do particípio e do artigo, pouca referência detêm como classe autônoma. $\mathrm{O}$ artigo não raramente é entendido como um tipo taxionômico que se inscreve na classe dos adjetivos ou dos pronomes. Dentre os pontos de convergência em todas as propostas, observa-se a unanimidade de referência ao verbo, à preposição e à conjunção como classes autônomas, bem como a ausência do numeral, uma invenção taxionômica que a gramática brasileira viria a consagrar com a edição da nomenclatura gramatical de 1959 (cf. Kury, 1961).

Quadro 3 - Classes de palavras em dez gramáticas brasileiras do século XIX

\begin{tabular}{|c|c|c|c|c|c|c|c|c|c|c|}
\hline & Art & Nom & & Pro. & Ver. & Adv. & Par. & Pre. & Con. & Int. \\
\hline & & Sub. & Adj. & & & & & & & \\
\hline Silva $^{17}$ & & - & • & & • & . & & • & • & • \\
\hline Duarte $^{18}$ & & - & - & & - & & & • & - & - \\
\hline Conduru ${ }^{18}$ & & $\bullet$ & - & & $\bullet$ & $\bullet$ & & - & $\bullet$ & $\bullet$ \\
\hline Reis $^{18}$ & & • & $\cdot$ & & • & • & & • & • & • \\
\hline Costa e Cunha & - & $\bullet$ & - & $\bullet$ & $\bullet$ & $\bullet$ & - & - & $\bullet$ & $\bullet$ \\
\hline Júlio Ribeiro & $\cdot$ & • & $\bullet$ & $\bullet$ & $\bullet$ & $\bullet$ & & $\bullet$ & $\bullet$ & \\
\hline João Ribeiro & & - & $\bullet$ & - & - & - & & • & - & - \\
\hline $\begin{array}{l}\text { Pacheco \& } \\
\text { Lameira }\end{array}$ & & • & $\bullet$ & • & - & • & & • & • & • \\
\hline Bôscoli & & - & - & - & - & - & & $\bullet$ & - & - \\
\hline Maximino Maciel & & $\bullet$ & - & $\bullet$ & $\bullet$ & • & & - & $\bullet$ & \\
\hline
\end{tabular}

Não há, como se percebe, qualquer referência ao conectivo como classe gramatical, ou parte do discurso, já que os modelos de que se servem nossos gramáticos são reformulações que as tradições racionalista e histórico-comparativa impuseram à proposta de classificação das palavras da gramática latina, em que não se cuida do termo conectivo como parte do discurso. Cabe, pois, investigar em que

17 Arrolam o artigo e os pronomes entre os adjetivos. 
medida a noção de conectivo percorre os textos gramaticais brasileiros produzidos neste momento de nossa historiografia gramatical.

Para dar conta dessa tarefa, convém partir do conceito que se atribui a esse tipo lexical na tradição das gramáticas de base filológica do século XX, sobretudo as que pertencem ao período da chamada 'geração $\mathrm{NGB}^{\text {'18}}$, visto que é efetivamente a partir dessa unificação metalinguística para o ensino básico que se chega a um razoável consenso a respeito das características basilares das classes de palavras. Podemos afirmar que, no corpo da doutrina norteadora dessas gramáticas, reúnem-se na noção de conectivo a preposição, a conjunção e o pronome relativo, tendo em vista o fato de expressarem ao menos um dos seguintes papéis gramaticais:
a) o papel de liame vocabular ou oracional;
b) o papel de indicação da fronteira vocabular ou oracional;
c) o papel de atribuidor de uma relação no plano sintático;
d) o papel de termo anafórico dotado de uma função sintática.

Embora não se detenham na explicitação desses papéis, a gramáticas da geração NGB a elas se referem claramente nas propostas de análise sintática, razão por que as aulas de língua portuguesa no período em foco, herdeiras do espírito analitista do período científico, também costumavam atribuir às classes gramaticais reunidas sob a rubrica de conectivos os referidos papéis. O papel de liame vocabular ou oracional, decerto, se aplica a todas as três classes nomeadas, não obstante se faça a ressalva de que o pronome relativo não é precipuamente um liame, senão uma palavra que cumpre a função de representar na oração subordinada a função sintática de um dos termos integrantes da oração principal. E é justamente por tal fato que a ele, pronome relativo, atribui-se singularmente o papel de termo anafórico ${ }^{19}$. Já o papel de atribuidor de uma relação, aplicando-se aqui a noção que se confere a esse termo na tradição racionalista como um processo de vinculação de ideias, é típico das preposições. Interessante notar que os gramáticos do período científico do século XIX atribuíam conceito mais amplo à relação, para nele expressarem a atribuição de valores semânticos como causa, tempo, posse, matéria, lugar, etc. Já o papel de indicar a fronteira oracional no período tem maior relevo no plano pedagógico, caso em que se inscreve, sobretudo, a classe das conjunções.

Não obstante fuja ao escopo deste estudo, cabe observar em rápidas linhas que as gramáticas brasileiras mais recentes ampliaram o emprego de hiperônimos metalinguísticos para referir-se às classes de palavras que exercem os papéis acima arrolados, tendo em vista sua filiação a um dado modelo teórico. Assim, ao lado do termo conectivo, leem-se com frequência os termos conector e transpositor, dada a renovada visão que se aplica aos papéis exercidos pelas classes das conjunções, das preposições, dos pronomes e do advérbio na estruturação da frase ${ }^{20}$. Uma outra

18 Por 'geração NGB' entendemos o grupo de gramáticos brasileiros que publicaram textos gramaticais pautados na tradição filológica, com influência subsidiária do estruturalismo linguístico, tendo como referência as bases metalinguísticas propostas pela Nomenclatura Gramatical Brasileira de 1959. Nesse sentido, pertencem à geração NGB não apenas os gramáticos que se filiaram às suas diretrizes, mas também os que o fizeram parcial ou restritivamente ou a elas se opuseram.

${ }^{19}$ Saliente-se que o metatermo anafórico não habita as páginas da gramática da geração NGB.

${ }^{20}$ Exemplos do emprego destes hiperônimos encontram-se em Azeredo (2008) e Bechara (1999). Em Neves, encontra-se ainda o termo junção: “Algumas palavras da língua que pertencem à esfera 
observação necessária reside no fato de que os estudos mais recentes, sobretudo os vinculados à teoria do texto e da enunciação, incluem os conectivos de maneira geral numa classe de operadores discursivos que cuidam do alinhavo do texto, numa missão de estabelecer vínculos de coesão interna e exofórica, fato que nos permitiria incluir entre os papéis dos conectivos acima referidos um item (e) instrumento de coesão textual. Como veremos adiante, esse papel não era estranho aos gramáticos brasileiros oitocentistas no tocante ao emprego da conjunção.

Voltando à presença do conectivo na base metalinguística da Nomenclatura Gramatical Brasileira, de imediato emerge seu emprego para referir-se a palavras que exerçam papel de liame sintático, conforme atesta sua definição em Kury (1961, p. 81): "palavras que estabelecem uma ligação ou conexão entre palavras ou partes de uma frase". Note-se, por sinal, que o texto oficial da NGB não inclui o metatermo conectivo, fato possivelmente resultante da ausência de consenso entre os gramáticos que a elaboraram no tocante a seus domínios. São conectivos as conjunções e as preposições, ou apenas as conjunções? Devemos incluir entre os conectivos o pronome relativo? Como se situam as denominadas "palavras denotativas" quanto ao papel de conexão? Essas são questões que os gramáticos da geração NGB foram solucionando segundo suas convicções pessoais, não obstante se tenha chegado a razoável consenso, conforme já se assinalou acima, de que são conectivos a preposição, a conjunção e o pronome relativo, com a ressalva de que a primeira se especifica no cumprimento dos papéis $a$ e $c$, a segunda no cumprimento dos papéis $a$ e $b$ e o terceiro no cumprimento dos papéis $b$ e $d$.

Nesse aspecto, revela-se uma clara linha de continuidade, que parte dos textos gramaticais oitocentistas - sobretudo se considerarmos as gramáticas do período científico - para desembocar nos textos da geração NGB. A pesquisa não nos esclareceu ainda em que obra específica se introduz o metatermo conectivo no âmbito da gramaticografia brasileira, mas evidencia-se sua circulação frequente entre os nomes mais representativos do século XIX. Em seu Dicionário gramatical (1906[1897], João Ribeiro (1860-1934) traça algumas referências ao conectivo como figura relevante na construção frasal, não obstante reconheça que, no contexto dos textos linguísticos então publicados, tratava-se de tipo lexical pouco referido: "Connectivo - termo pouco usual. Palavra de relação entre as proposições" (1906[1897], p. 70). Como se percebe, o fato de Ribeiro haver reservado um verbete exclusivo para o lema conectivo já o caracteriza efetivamente como um metatermo da gramaticografia brasileira dos Oitocentos, apesar de "pouco usual".

Em outras referências, Ribeiro traça juízo mais esclarecedor sobre a natureza do conectivo, como se percebe na seguinte passagem: "As proposições coordenadas são syndeticas ou asyndeticas, e quanto á natureza dos seus connectivos, dividem-se em copulativas, adversativas, disjuntivas e conclusivas" (1906[1897], p. 82). Os dois fragmentos até aqui citados já nos auxiliam na tarefa de investigar a noção gramatical que se atribuía ao conectivo, em que o papel de liame sintático e instrumento relacional nem sempre se irmanam nas propostas de descrição taxionômica.

semântica das relações e processos atuam especificamente na junção dos elementos do discurso, isto é, ocorrem num determinado ponto do texto indicando o modo pelo qual se conectam as porções que se sucedem (2000, p. 601). 
Veja-se que, no primeiro fragmento citado, Ribeiro denomina os conectivos "palavras de relação", sem qualquer referência ao papel de liame entre proposições; aqui não se pode afastar a hipótese de que Ribeiro incluísse na expressão "palavras de relação" a dupla interpretação dos conectivos como liames e instrumentos relacionais. Já no segundo fragmento, os conectivos surgem como palavras gramaticais responsáveis pela atribuição do valor semântico-relacional entre as proposições, visto que a classificação proposta para as proposições assindéticas edifica-se "quanto à natureza de seu conectivo".

Observe-se, agora, o seguinte trecho da mesma obra de João Ribeiro, em que se traça um juízo mais aprofundado sobre o tema (1906[1897], p. 266):

\begin{abstract}
Os CONNECTIVOS são os termos que ligam uma proposição a outra: mas, $e$, ou, etc.: Julio desapareceu ou morreu; estuda, mas não aprende; estuda $e$ aprende. Esses exemplos representam connectivos proposicionaes ou syntacticos, por isso que ligam phrases. Os connectivos léxicos são os que ligam vocábulos: Pedro com Antonio; estar em Paris. Essas duas subdivisões nada têm que vêr com as categorias grammaticaes, e por isso o connectivo syntactico póde ser representado por advérbios e por adjectivos conjunctivos ou locuções equivalentes: Casa em que Socrates morreu; casa onde Sócrates nasceu; nasceu, sofreu, depois morreu; veio, logo foi empregado, e merecidamente. Da mesma sorte, o connectivo vocabular, que é em regra uma preposição ${ }^{21}$, póde ser representado pela conjuncção ou equivalente: Dous $e$ oito são dez; cinco mais seis, onze.
\end{abstract}

Nítida, nesse trecho, a observação de que o termo conectivo, já no ambiente acadêmico dos Oitocentos, circulava como um hiperônimo metalinguístico para algumas classes gramaticais ${ }^{22}$, notadamente a conjunção, a preposição, o adjetivo conjuntivo (também pronome relativo) e o advérbio. A inclusão do advérbio, aqui, se deve não só ao caráter adverbial de pronomes relativos como onde e aonde, também denominados pronomes adverbiais, como também ao caráter copulativo que o advérbio mais, de mesmo étimo da conjunção mas, assume quando interposto entre núcleos do sintagma $a^{23}$.

No âmbito das gramáticas, especificamente, o termo conectivo não goza de prestígio, possivelmente devido ao fato de não designar uma classe gramatical única, específica, fato que inibiria sua inclusão no conjunto das partes do discurso. A ausência, entretanto, é suprida aqui e ali em referências genéricas. Maximino Maciel, por exemplo, ao tratar dos pronomes relativos, adverte que tais pronomes também são denominados "conjuntivos, porque servem de connectivos às proposições, de sorte que o termo conjuntivo nos parece mais apropriado, mais característico" (1922[1894]: p. 127). Veja que, aqui, o emprego do termo não tem propriamente valor metalinguístico, já que visa a justificar a denominação de conjuntivos para os pronomes relativos em face de sua semelhança construcional com as conjunções.

${ }^{21}$ No original "proposição", por erro óbvio.

22 A hesitação de uso entre os termos partes do discurso, classes gramaticais e categorias gramaticais constitui tema que merece estudo especializado, razão por que não nos ocupamos de sua análise neste estudo.

23 Ao fazer referência às línguas africanas no verbete negro, João Ribeiro assinala: "É de notar-se igualmente a reação que o portuguez exerceu a seu turno sobre a língua africana. Essa reação affecta a própria grammatica com a adopção de certos connectivos e preposições” (1906[1897], p. 221). Observe-se que conectivo e preposição aqui são referidos como entidades gramaticais distintas. 
Em outras palavras, para Maciel o papel de conectivo é originalmente o que exercem as conjunções.

Encontra-se, por outro lado, em Manuel Pacheco da Silva Júnior (1842-1899) e Boaventura Plácido Lameira de Andrade (?-?) uma referência às palavras conectivas ou relativas, em oposição às palavras nominativas ou ideais, fruto do viés positivista que lhes impunha maior pendor pelos temas taxionômicos (1887, p. 76):

Tocante ás suas funções naturaes, dividem-se as palavras em:

a) Nominativas, ideaes (dependentes e independentes). São as que servem para distinguir os seres, as substancias reaes ou abstractas, as qualidades e acções, os diversos estados das pessoas e cousas, todas as manifestações da vida (nome e verbo).

b) Connectivas ou relativas. São as que exprimem as numerosas relações de tempo, logar, numero, quantidade, causa, efeito, etc. (preposição e conjunção).

Mais afeitos ao viés diacrônico, fato que lhes conferia acentuado comprometimento com os modelos de descrição gramatical nas línguas clássicas, Silva Jr. e Andrade vão além do latim, para referirem-se a uma concepção unificada da preposição e da conjunção como "palavras conectivas" na tradição gramatical grega. E assim destacam: "Os grammaticos gregos classificam as preposições com as conjuncções, sob o nome de connectivas (sundesmos)" (1887, p. 109). Cuida-se aqui de uma referência à classe mais genérica dos conectivos presente na Poética de Aristóteles, que s.m.j. não tem par na gramaticografia brasileira dos Oitocentos.

Em princípio, a referência de Pacheco e Lameira a esse fato da gramatização do grego soa como uma informação menos relevante, não obstante enriquecedora como viés descritivo da preposição e da conjunção, visto que sua posição é claramente favorável ao tratamento distinto das duas classes gramaticais em questão. Entre os primeiros intérpretes da Poética de Aristóteles - podemos citar Amônio Sacas (175-240), Anício Boécio (480-525) e James Harris (1709-1780), cujas referências se podem encontrar em Arens (1984) -, há reiterado entendimento do súndesmos, também sýndesmos, como liame, ligadura que torna muitos em um. O termo é efetivamente usado por Aristóteles como uma das quatro categorias linguísticas: ónoma, rhèma, árthron e sýndesmos ${ }^{24}$, embora, conforme nos ensina Neves (1981, p. 65), a noção de sýndesmos em Aristóteles nem sempre tenha significação gramatical, senão a de um recurso estilístico que faz de muitas coisas uma unidade ${ }^{25}$. No que tange ao nosso interesse nessas linhas, a citação de Pacheco e Lameira ao termo aristotélico, que por sinal se faz sem o cuidado da referência bibliográfica, serve para atestar a postura mais ortodoxa desses gramáticos dentro do paradigma da escola históricocomparativa.

Saliente-se, na esteira dessa referência às línguas clássicas, que na gramática latina a preposição e a conjunção são interpretadas sintaticamente de modo distinto. A preposição é ordinariamente entendida como a parte do discurso que se posiciona antes de uma outra, completando, alterando ou diminuindo sua significação ${ }^{26}$. Já a

\footnotetext{
${ }^{24}$ Para aprofundamento do tema, leia Swiggers (1997) e Laspia (1997).

25 Neves traça referência específica ao uso do termo no livro 3 da Retórica.

26 Em Donato (2007), lê-se: "Pars orationis, quae preaposita aliis partibus orationis significationem
} 
conjunção é a parte do discurso que estabelece um vínculo entre duas outras na organização da proposição (sententia $)^{27}$. Essa interpretação distintiva das duas classes gramaticais perdurou nas gramáticas de línguas vernáculas, de tal sorte que sua visão unificada como tipos de conectivos somente se fez notar a partir dos estudos realizados no século XIX.

Efetivamente, não se pode atribuir à preposição o caráter de um mero liame vocabular, visto que seu papel, no plano diacrônico das línguas românicas, inclui a atribuição de valor sintático aos termos da oração, papel que no paradigma das línguas sintéticas, como o latim erudito, era cumprido pela flexão desinencial de caso. Nesse diapasão, merece destaque a observação de Pacheco e Lameira de que a definição dos gramáticos latinos "era errónea, e não indicava a natureza interna da preposição", pois que "em latim ella nem sempre precedia o nome ou verbo (Tenus colloca-se depois do ablativo ; cum, depois de me, te, se, nobis, vobis, qui)" (1887, p. 109). Salientam os autores que "no portuguez, porem, sempre a preposição é precedente" (1887, p. 109), fato que, afinal, legitimou a definição dos gramáticos latinos para além do próprio latim.

\section{A NATUREZA CONECTIVA DO PRONOME RELATIVO, PREPOSIÇÃO E DA CONJUNÇÃO}

No item 4 deste estudo, fizemos menção aos papéis atribuídos aos conectivos pela tradição gramatical de base filológica: a) papel de liame vocabular ou oracional; b) papel de indicação da fronteira vocabular ou oracional; c) papel de atribuidor de uma relação no plano sintático; d) papel de termo anafórico dotado de uma função sintática. Para termos ideia do entendimento com que os gramáticos brasileiros do século XIX descreviam o emprego dos conectivos, tomando por base essas premissas, leiamos um conjunto de definições para cada uma das classes gramaticais estudadas.

\subsection{Definições de pronome relativo ${ }^{28}$}

Oferecem-se, a seguir, oito definições, extraídas do corpus sob análise, identificadas segundo o papel específico dos conectivos referido no item 4 . Destacamos algumas palavras-chave para melhor percepção dos valores gramaticais expressos pelo gramático.

I. [Adjetivos] Demonstrativos Conjunctivos são os que mostrão ou o sujeito, ou o atributo de uma oração antecedente e unem ao mesmo tempo as orações parciais com as de que são parte (Duarte, 1877[1829], p. VIII). (papéis a e d)

earum aut complet aut mutat aut minuit". Uma recente tradução da Arte de Donato para o português encontra-se em Dezotti (2011). Em Prisciano (1855, p. 24): "Est igitur praepositio pars orationis indeclinabilis, quae praeponitur aliis partibus vel appositione vel coinpositione".

27 Em Donato (2007), lê-se: "Pars orationis adnectens ordinansque sententiam". Em Prisciano (1855, p. 93) lemos: "Coniunctio est pars orationis indeclinabilis, coniunctiva aliarum partium orationis".

28 Também pronome conjuntivo, adjetivo relativo ou adjetivo conjuntivo. 
II. [Adjetivos] Demonstrativos relativos são os que se referem a pessoas, a cousas, ou a juízos enunciados em frase antecedente (Condurú, 1840, p.12). (papel d)

III. Adjectivo conjuntivo, é, como sôa a palavra, o que tem a virtude de conjunctar proposições, fazendo as vezes de conjuncção: liga proposições incidentes a outras por ellas modificadas, isto por meio de dois termos de relação, um na proposição modificada, outro na modificante, dos quaes o primeiro se chama o seu antecedente, o segundo o seu consequente (Reis, 1871[1866], p. 30). (papéis a e c)

IV. [Adjetivos] Conjunctivos são os que conjuctam cláusulas [...]. Os conjunctivos referem-se a alguma cousa já expressa em outra proposição, mas cuja determinação elles mais tornam precisa (Silva Jr. \& Andrade, 1887, pp. 87-93). (papéis a e d)

V. É conjunctivo ou relativo o adjectivo que estabelece relação entre duas clausulas (Bôscoli, 1898[1893], p. 80). (papel c)

VI. Os adjectivos conjunctivos referem-se sempre a um nome de clausula principal: esse nome chama-se antecedente (Ribeiro, 1910[1881], p. 248). (papel d)

VII.[Adjetivos] Relativos são os que se referem a nome ou pronome, que é determinado ou qualificado pela proposição [...]. Vê-se, pois, que o relativo substitue o nome e ao mesmo tempo faz as vezes de conjuncção, ligando o nome determinado com a proposição determinante que se segue. Por isso póde também ser denominado nome conjunctivo. (Ribeiro, 1930[1889], p. 82). (papéis a e d)

VIII.Pronome relativo é aquelle que, conjuntando duas proposições, sempre se refere a um nome anteriormente expresso (Maciel, 1922[1894], p. 127). (papéis a e d)

A leitura dessas definições, em princípio, revela uma visão do pronome relativo significativamente uniformizada entre as gramáticas racionalistas e científicas. Há expressiva predominância do papel de liame, a que se segue o papel de instrumento anafórico. Por sinal, conforme se verá nas definições de preposição e conjunção, esse papel anafórico é o que mais distingue o pronome relativo no conjunto dos conectivos, razão por que, embora não seja o elemento de perfil mais presente nas definições estudadas, constitui-se, sem dúvida, no que detém caráter mais distintivo.

O fato de não se fazer referência ao pronome relativo como instrumento gramatical que determina a fronteira oracional bem expressa a noção de que aqui temos uma subclasse gramatical que trabalha mais na arquitetura sintática da frase do que no estabelecimento da topologia sintática, sobretudo levando-se em conta que o pronome relativo, de modo geral é caracterizado como termo sintático da oração subordinada. Em outras palavras, não lhe cumpre estabelecer as fronteiras oracionais exatamente em face de sua posição interna a uma das proposições sintaticamente vinculadas. 


\subsection{Definições de preposição}

Passemos às definições da classe das preposições:

I. Preposição é uma parte invariavel da oração, que posta entre duas palavras, mostra que a segunda está completando a primeira, como: Vou para casa de João. A Preposição rege, isto é, demanda depois de si uma palavra, e mostra só a relação de complemento, isto é, que ella com a palavra seguinte está completando a significação de outra palavra antecedente (Duarte, 1877[1829], p. 94). (papéis b e c)

II. Preposição é a parte da oração que, posta entre duas palavras, faz que a segunda restrinja, complete ou modifique a significação da primeira (Condurú, 1840, p. 66). (papéis b e c)

III. Preposição é a parte invariável da oração que exprime uma relação entre duas palavras, ou entre um termo antecedente e outro consequente, ligando o segundo ao primeiro (Reis, 1871[1866], p. 139). (papel c)

IV. Preposição é uma palavra que liga um substantivo ou um pronome a outro substantivo, a um adjetivo, a um verbo, mostrando a relação que há entre elles (Ribeiro, 1910[1881], p. 71). (papéis a e c)

V. Preposição é uma palavra intervocabular que indica a relação syntactica entre dous termos (Maciel, 1992[1894], p. 141). (papéis b e c)

VI. Preposição é uma partícula invariável que serve para ligar duas palavras (subst. ou pronome a substantivo, pronome, adjectivo ou verbo) com o fim de indicar-lhes a mutua relação (Silva Jr. \& Andrade, 1887, p. 109). (papéis a e c)

VII. Preposição é a parte que posta entre dous vocábulos determina a natureza da relação que existe entre elles (Ribeiro, (1930[1889], p. 102) ${ }^{29}$. (papéis b e c)

VIII. Preposição é a palavra que liga dous termos, mostrando de modo determinado a relação existente entre elles (Bôscoli, 1898[1893], p. 88). (papéis a e c).

Perceptível, nessas definições, a predominância do papel relacional, seja nas gramáticas racionalistas, seja nas científicas. O papel de liame vocabular revela-se secundário, ao passo que o papel anafórico evidentemente não se aplica às preposições. A análise das definições, ainda que superficial, revela que a noção de instrumento sintático atribuidor de uma dada função, fato mais flagrante na definição de Filipe Condurú, é o principal traço caracterizador da preposição.

29 Em outra referência, Ribeiro atesta que a preposição “é uma palavra relativa, que com o seu complemento necessário fórma um adverbio ou locução adverbial: com ardor = ardentemente, etc." (1930[1889], p. 105). Há, nessas observações, clara noção do papel da preposição como transpositor. 


\subsection{Definições de conjunção}

Por derradeiro, leiamos as definições de conjunção:

I. Conjuncção é uma parte da oração, que ata e ordena entre si as orações, para fazerem um corpo de período, e um discurso continuado (Duarte, 1877[1829], p. 100). (papéis a e f)

II. Conjunção é uma palavra invariável, que une as partes homogêneas da oração ou do discurso, indicando conveniencia, oposição, dependencia ou condição entre ellas (Condurú, 1840, p. 68). (papéis a e c)

III. Conjunç̧ão, é uma parte invariável da oração que liga uma palavra á outra, uma proposição á outra, um sentido a outro, ou um termo antecedente a outro consequente (Reis, 1871[1866], p. 153). (papel a)

IV. Conjuncção é uma palavra que liga sentenças entre si, e que prende também entre si palavras usadas do mesmo modo em uma sentença (Ribeiro, 1910[1881], p. 72). (papel a)

V. Conjuncção (lat. conjunctionem, de cum jungere) é a palavra invariável e relacional, que serve para ligar palavras e proposições (Silva Jr. \& Andrade, 1887, p. 112). (papel a)

VI. Conjuncção é a palavra que serve para indicar as relações entre duas proposições (Ribeiro, 1930[1889], p. 103). (papel c)

VII. Conjuncção é a palavra que liga asserções entre si [...]. A conjuncção é um poderoso elemento pâra (sic) relacionar asserções; sem ella todo o discurso seria um esqueleto sem colorido (Bôscoli, 1898[1893], p. 91). (papel a, c e f)

VIII. Conjunção é uma palavra invariável que liga duas proposições e ás vezes duas palavras (Maciel, 1922 [1894], p. 145). (papel a)

No tocante às conjunções, evidencia-se a predominância de seu papel como liame vocabular ou oracional - o que, por sinal, só não se expressa em uma única definição -, fato que a distingue das demais palavras conectivas no tocante à ausência de papel relacional. O papel anafórico pode-se incluir, em parte, na constatação do papel de instrumento de coesão textual verificado em Bôscoli e Costa Duarte, não obstante haja nessas definições um conceito de vinculação entre elementos textuais bem mais amplo do que o da simples anáfora. A expressão "para fazerem um corpo no período e um discurso continuado" em Duarte é nitidamente caracterizadora de uma visão construcional da conjunção como classe indispensável para a arquitetura e organização semântico-sintática do texto, ainda que o metatermo texto, obviamente, não esteja presente entre as palavras do gramático maranhense.

Diga-se o mesmo da passagem "sem ella todo o discurso seria um esqueleto sem colorido" de que se serve Bôscoli, metaforicamente, para justamente corroborar a tese da indispensabilidade da conjunção como instrumento de coesão textual. A ideia do papel exercido pela conjunção como classe que "dá cor ao esqueleto" e, na melhor exegese, a de que um texto sem conjunções não atinge o desiderato necessário de transmitir seu conteúdo semântico com clareza, eficácia e estilo. 


\section{CONCLUSÃo}

O percurso dos estudos gramaticais brasileiros no século XIX segue uma linha de continuidade, em que se reúnem sob a rubrica conectivos as classes do pronome relativo, da preposição, da conjunção e do advérbio, esse último quando em função análoga à do pronome relativo ou da conjunção intervocabular. Não obstante a distinção conceptual acerca da descrição linguística entre as gramáticas do Período Racionalista e do Período Científico, percebe-se certa linha de continuidade no tocante ao reconhecimento da preposição, da conjunção e do pronome relativo (conjuntivo) como partes do discurso, não obstante seu reconhecimento como termo conectivo seja expressivamente divergente.

Conclui-se, ademais, que embora o termo conectivo não seja propriamente um metatermo no âmbito das gramáticas, raramente referido em textos avulsos e nos dicionários gramaticais, verifica-se haver uma clara noção de seu emprego como hiperônimo da preposição, da conjunção e do pronome relativo (conjuntivo), bem como, numa certa medida, do advérbio, para designar um certo termo que cumpre uma das funções especificadas no item 4 deste estudo.

Por outro lado, os referidos papéis que essa geração de gramáticos atribui aos conectivos - liame vocabular e oracional, estabelecimento da fronteira vocabular e oracional, instrumento de uma relação e instrumento anafórico - são os mesmos que, em medidas distintas, se aplicam na conceituação dos conectivos no século XX, pelo menos até a época da Geração NGB, com a ressalva de que um quinto papel, o de instrumento de coesão textual, que entraria no panorama acadêmico brasileiro nas décadas derradeiras do século passado, com a chegada do estudo da enunciação e da teoria do texto, também se encontra pontualmente em pelo menos dois gramáticos oitocentistas, Antonio da Costa Duarte e José Ventura Bôscoli, curiosamente pertencentes a períodos historiográficos distintos da gramaticografia do português no Brasil.

\section{REFERÊNCIAS}

Arens H. Aristotle's theory of language, texts form 500 to 1750. Amsterdam/Philadelphia: John Benjamins Publishing Company; 1984.

Assunção C da C. António de Morais Silva - um gramático inovador. Anais do Sexto Congresso da Associação Internacional de Lusitanistas. Rio de Janeiro, 8-13 de agosto de 2001. [citado 4 abr. 2010]. Disponível em: http://www.oocities.org/ail_br/antoniomoraessilvaumgramatico.html.

Ayer N-LC. Grammaire comparéé de la langue française. 4a ed. Bale, Genève e Lyon: H. Georg, Libraire-Éditeur; 1885[1876].

Azeredo JC de. Gramática Houaiss da língua portuguesa. São Paulo: Publifolha; 2008.

Bain A. A higher English grammar. London: Longmans, Green, and Co; 1875.

Bartlett BE. Metalanguage as object-language. In: Auroux, S et al. Matériaux pour une histoire ds théories linguistiques. Lile: Université de Lille; 1984. p. 517-524.

Bôscoli JV. Grammatica portugueza. 2a ed. Rio de Janeiro: [editora desconhecida]; 1898[1893]. 
Braga T. Grammatica portugueza elementar - fundada sobre o methodo histórico-comparativo. Porto/Rio de Janeiro: João E da Cruz Coutinho/AA Cruz Coutinho; 1876.

Burggraff P. Principes de grammaire générale ou exposition raisonnée des éléments du langage. Liége: Imprimerie de H. Dessain; 1863.

Câmara Jr JM. Os estudos de português no Brasil. In: Dispersos. Rio de Janeiro: Fundação Getúlio Vargas; 1972.

Cavaliere R. A corrente racionalista da gramática brasileira no século XIX. In: Cavaliere R. A gramática no Brasil: ideias, percursos e parâmetros. Rio de Janeiro: Lexikon Digital; 2014a. p. 44-58.

2014b.

. A gramática no Brasil: ideias, percursos e parâmetros. Rio de Janeiro: Lexikon Digital;

Antonio de Moraes Silva e os estudos gramaticais do século XVIII. In: Thielemann W, organizador. Século das Luzes: Portugal e Espanha, o Brasil e a Região do Rio da Prata. Frankfurt am Main: TFM - Teo Ferrer de Mesquita; 2006. p. 537-540.

. Fonologia e morfologia na gramática científica brasileira. Niterói: Eduff; 2000. 2002;23:102-120

Uma proposta de periodização dos estudos linguísticos no Brasil. Confluência.

Coelho FA. A lingua portugueza; noções de glotologia geral e especial portugueza. Porto: Livraria Universal; 1881.

. A lingua portugueza; phonologia, etymologia, morphologia e syntaxe. Coimbra: Imprensa da Universidade; 1868.

Conduru FB de O. Gramática elementar da língua portuguesa. Maranhão: Typ. do Paiz; 1840.

Costa e Cunha AE da. Grammatica elementar portugueza, adaptada ao ensino das escolas de instrucção primaria, quer dos menores, quer dos adultos, e bem assim dos Collegios, Liceos e Escolas Normaes e aulas preparatorias. Rio de Janeiro: [editora desconhecida]; 1880.

Dal Ri Jr. A. Evolução histórica e fundamentos políticos jurídicos da cidadania. In: Dal Ri Jr. A; Oliveira, OM de, organizadores. Cidadania e nacionalidade: efeitos e perspectivas: nacionais regionais - globais. Ijuí: Ed. da Unijuí; 2002.

Dal Ri L. Espaço jurídico. A construção da cidadania no Brasil, entre Império e Primeira República. Espaço Jurídico. 2010;11(1):7-36.

Dezotti LC. Arte menor e arte maior de Donato: tradução, anotação e estudo introdutório [dissertação]. Universidade de São Paulo, Faculdade de Filosofia, Letras e Ciências Humanas. São Paulo; 2011.

Donatus A. Ars minor: de partibus orationis. I Intratext Edition CT.; 2007. [citado 5 out. 2016]. Disponível em: http://www.intratext.com/X/LAT0192.htm .

Duarte A da C. Compendio da grammatica philosophica da língua portugueza. $6^{\mathrm{a}}$ ed. Maranhão: Antonio Pereira Ramos d'Almeida editor; 1877[1829].

Elia S. Os estudos filológicos no Brasil. In: Elia, S. Ensaios de Filologia e Lingüística. São Paulo: Editora Grifo; 1975.

Fávero LL, Molina MAG. As concepções lingüísticas no século XIX. Rio de Janeiro: Editora Lucerna; 2006. 
Fortes IF. Arte de grammatica portuguesa. Rio de Janeiro: Impressão Régia; 1816.

Gonçalves MF. Gramáticas do português na transição do século XIX para o século XX: a "gramática científica". La lengua, lugar de encuentro: actas del XVI Congreso Internacional de la ALFAL. Alcalá de Henares; 2012. p. 2571-2579.

Koerner EFK. "Metalanguage" in linguistic historiography. In: Koerner EFK. Professing linguistic historiography. Amsterdam/Philadelphia: John Benjamins; 1995. p. 27-46.

The natural science impact on theory formation in $19^{\text {th }}$ and $20^{\text {th }}$ century linguistics. In: Koerner EFK. Professing Linguistic Historiography. Amsterdam/Philadelphia: John Benjamins Publishing Co.; 1995. p. 47-76.

Continuities and discontinuities in the history of linguistics. In: Koerner EFK. Practicing Linguistic Historiography; selected essays. Amsterdam/Philadelphia: John Benjamins Publishing Company; 1989. p. 69-78.

Kury A da G. Pequena gramática para a explicação da nova nomenclatura gramatical. Rio de Janeiro: Livraria Agir Editora; 1961.

Laspia P. L'articolazione linguistica; origini biologiche di una metáfora. Roma: La Nuova Italia Scientifica; 1997.

Maciel M de A. Grammatica descriptiva. $8^{a}$ ed. Rio de Janeiro: Livraria Francisco Alves; 1922[1894].

Maciel M. Philologia portugueza: ensaios descriptivos e historicos sobre a lingua vernacula. Rio de Janeiro: Typ. de José de Oliveira; 1889.

Melo GC de. Gramática fundamental da língua portuguesa. $2^{a}$ ed. Rio de Janeiro: Livraria Acadêmica; $1970[1967]$.

Murakawa C de AA. Léxico e gramática no Diccionario da Lingua Portugueza (1813) de António de Morais Silva. Alfa. 2006;50(2):55-67.

Nascentes A. A filologia portuguesa no Brasil. In: Nascentes A. Estudos filológicos. Rio de Janeiro: Civilização Brasileira; 1939.

Neves MH de M. A teoria linguística em Aristóteles. Alfa. 1981;25:57-67. Gramática de usos da língua portuguesa. São Paulo: Editora Unesp; 2000.

Parreira AD. Contribuición a la historia de la gramatica brasileña del siglo XIX. [tese]. Salamanca: Universitad de Salamanca, Faculdade de Filologia; 2011.

Prisciani. Institutionum grammaticarum. In: Keilii H. Grammatici Latini. Lipsiae: In Aedibus B.G. Tevbneri; 1855.

Reis FS. Grammatica portugueza, acomodada aos princípios geraes da palavra seguidos de immediata applicação pratica. $2^{\mathrm{a}}$ ed. Maranhão: Typographia de R d'Almeida \& C; 1871[1866?].

Ribeiro EC. Serões grammaticaes ou nova grammatica portugueza. Bahia: Livraria Catilina de Romualdo dos Santos; 1890.

Ribeiro João. Diccionario gramatical. $3^{\text {a }}$ ed. Rio de Janeiro/São Paulo/Belo Horizonte: Livraria Francisco Alves; 1906[1897].

Grammatica portugueza, curso superior. 21 a ed. Rio de Janeiro/São Paulo/Belo

Horizonte: Livraria Francisco Alves; 1930[1889]. 
Ribeiro Julio. Grammatica portugueza. 10ª ed. Rio de Janeiro/São Paulo/Belo Horizonte: Livraria Francisco Alves; 1911[1881].

Traços geraes de linguistica. São Paulo: Livraria Popular de Abilio A. S. Marques; 1880.

Ricken U. Grammaire et philosophie au siècle des lumières. Lille: Publications de l'Université de Lille III; [data desconhecida].

Santos MHP. As ideias linguísticas portuguesas na centúria de Oitocentos. Lisboa: Fundação Calouste Gulbenkian; 2010. 2 vol.

Silva Jr MP da, Andrade BPL de. Noções de grammatica portugueza. Rio de Janeiro: J.G. de Azevedo Editor; 1887.

Silva A de M. Diccionario da língua portugueza. $4^{a}$ edição, enriquecida por Theotonio José de Oliveira Velho. Lisboa: Na Impressão Regia; 1831[1789].

1806.

. Epitome da grammatica da lingua portugueza. Lisboa: Off de Simao Thaddeo Ferreira;

Silva AF da. Grammatica portugueza. 9a ed. São Paulo: Augusto Siqueira \& Comp; 1906[1875].

Swiggers P. The syndesmos in Ancient Greek grammar: grammatical status and subtypes. Proceedings of the $16^{\text {th }}$ International Congress of Linguistics. [cd-rom]. Oxford: Pergamon; 1997.

Tracy AD. Élémens d’idéologie, second partie. Grammaire. Paris: Courciér Imprimeur-Librairie; 1803. [citado 5 jul. 2010]. Disponível em: https://archive.org/details/projetdlmentsdi00comgoog . 